Article

\title{
A Capability Approach to Understanding Sport for Social Inclusion: Agency, Structure and Organisations
}

\author{
Naofumi Suzuki \\ Graduate School of Social Sciences, Hitotsubashi University, Tokyo 186-8601, Japan; E-Mail: naofumi.suzuki@r.hit-u.ac.jp
}

Submitted: 5 February 2017 | Accepted: 6 April 2017 | Published: 29 June 2017

\begin{abstract}
Despite the global diffusion of the term social inclusion, as well as the use of sport to promote it, questions have been raised regarding the extent to which sport is able to contribute to transforming the exclusive nature of the social structure. The lack of analytical clarity of the concept has not helped to address these questions. This article proposes a conceptual framework based on Amartya Sen's capability approach, considering social exclusion as the denial of social relations that leads to serious deprivation of important capabilities. A person's capabilities could potentially be improved through micro-, meso-, and macro-level social processes. At the micro level, sport-based social inclusion programmes could offer such social relations to varying degrees, though sport's values are only relative to other leisure activities. The scale of impact depends primarily on the meso-level processes, in which the size and quality of each programme can be improved through organisational learning, and secondarily on the macro-level processes whereby the organisational population is institutionalised. It is argued that more research needs to be done on the meso and macro levels, as they are concerned with the ultimate potential of sport to facilitate structural transformation towards more socially inclusive society.
\end{abstract}

\section{Keywords}

capability approach; legitimation; social change; social inclusion; sport

Issue

This article is part of the issue "Sport for Social Inclusion: Questioning Policy, Practice and Research", edited by Reinhard Haudenhuyse (Vrije Universiteit Brussel, Belgium).

(C) 2017 by the author; licensee Cogitatio (Lisbon, Portugal). This article is licensed under a Creative Commons Attribution 4.0 International License (CC BY).

\section{Introduction}

The last few decades have seen the global spread of the term 'social inclusion' as a desirable policy objective (World Bank, 2013). It first became prevalent in European social policy in the late 1990s and diffused globally in the 2000s. The use of sport for the purpose of social inclusion took a similar path, booming in the early 2000s in the United Kingdom (Collins, 2003; Crabbe et al., 2006; Nichols, 2007), before expanding to the Global South in the mid to late 2000s (Coalter, 2007; Spaaij, Magee, \& Jeanes, 2014).

However, questions have been raised regarding the extent to which sport is able to be an effective vehicle for social inclusion. Much empirical research indicates that programmes using sport to promote social inclusion tend to benefit a limited number of participants on personal levels without changing the exclusive nature of the social structure (Coalter, 2015; Collins \& Haudenhuyse, 2015; Kelly, 2010; Spaaij et al., 2014). However, few have systematically attempted to assess sport's potential for transforming the social structure.

Meanwhile, a number of commentators have argued that the concepts of social exclusion and inclusion are so vaguely defined that underlying political ideologies are blurred and analytical precision is lacking (Levitas, 1998; Sen, 2000; Silver, 1994). This vagueness has inevitably affected the quality of research to evaluate sport-based interventions, as the difference between sporting inclusion and social inclusion through sport has often not been clearly distinguished in scholarly analyses (Coalter, 2002; Long et al., 2002; Suzuki, 2005).

This article proposes a conceptual framework so as to achieve two objectives: firstly, to clarify the relationship between sporting and social inclusion, and secondly, to approach questions relating to sport's potential for 
structural transformation. Amartya Sen's capability approach is its normative and analytical foundation. The core framework was first constructed for the first case study described below (Suzuki, 2005). Following this, the author then turned his attention to processes of organisational development, both at the levels of individual organisation (Suzuki, 2014) and of organisational population (Suzuki \& Kurosu, 2012). This article intends to refine the framework incorporating these two levels.

This article resonates with Svensson and Levine's (2017) call for using Sen's capability approach as the normative framework to guide 'Sport for Development and Peace' (SDP) practice, policy and research. They argue that the capability approach, with its emphasis on people-centred, localised processes to increase the capabilities of the underprivileged, is useful for SDP stakeholders to relativise the role of sport in development and thus to avoid seeing sport as only having positive influences on development and peace-building. While the author fully agrees with this normative position, this article is intended to demonstrate that the capability approach could also be the foundation of a rigorous analytical framework, when it is coupled with established sociological theories. It is true that sport often divides society and functions as an exclusive instrument. The policy and practice of SDP have been also criticised for its overoptimism and hegemonic nature (Coalter, 2010). This article, therefore, is in part aimed at providing a framework to critically examine the potential of the SDP sector as a whole; to what extent can sport realistically be the vehicle of positive social transformation?

To substantiate the argument, reference is made to three case studies conducted separately during a twelveyear period. The first study was conducted between 2004 and 2005, investigating a sport-based programme aimed at helping young people living in disadvantaged neighbourhoods in Glasgow, Scotland (Suzuki, 2007). It was during the period when the then Labour government placed 'tackling social exclusion' at the heart of British social policy. In Scotland, Social Inclusion Partnerships (SIPs) were set up to address a range of issues relevant to urban deprivation. The programme was funded through one of them. Thus, the study was explicitly designed to consider whether and how sport might contribute to 'social inclusion' in that context.

The second study was to examine the process of organisational development of an SDP programme based in Lesotho (Suzuki, 2014). Although 'social inclusion' was not explicitly on its agenda, the similarity with the first project was evident in that it was aimed at assisting young Basotho suffering from poverty and deprivation. Originally launched as a programme offering HIV/AIDS education and life skills training using football, it has now evolved into an elite football club whose mission is to provide comprehensive assistance to young people in Lesotho.

The third study is currently in progress, using the style of action research, with the author being on the steering committee of a football-based homeless assistance pro- gramme. The committee, established in 2015, is called the 'Sport for Social Inclusion Working Committee'. The core members had been running the football team set up by the Big Issue Foundation mainly for vendors of the Big Issue Japan since 2008. It is now looking to develop a network of social and youth work organisations centred on an inclusive football tournament called the Diversity Cup.

The following section first explains the conceptual framework based on Sen's understanding of social exclusion, followed by the analysis section which elaborates on the framework in relation to empirical evidence from the case studies. The final section summarises the overall argument and the merits of the capability approach to the study of sport for social inclusion.

\section{Conceptual Framework}

\subsection{Capability Approach and Social Exclusion/Inclusion}

Sen (2000), unimpressed by 'an indiscriminate listing of problems under the broad heading of "social exclusion" and...a lack of discipline in selection' (p. 2), contends that the concept should be understood in close relation to the more traditional literature of poverty and deprivation research. In his view, the usefulness of the term lies in its refocusing of people's attention to the relational features of poverty and deprivation. For Sen, social exclusion simply means failed social relations that lead to serious capability deprivation.

The notion of capability reflects Sen's normative position that a person's well-being should be assessed in terms of the extent of the freedom they have in leading their life (Sen, 1992, 1999). Given the diversity of human beings, equality in such variables as primary goods, resources, income and utility does not assure equality in achieved levels of well-being. Thus, the evaluation of human lives starts from identifying the elements that constitute one's well-being. Sen calls these elements 'functionings' or 'beings and doings'. A person converts their resources into a set of 'beings and doings'. Human beings vary in terms of the ability to convert the same amount of resources into functionings. Capabilities are concerned with this ability. To assure equality in achieved levels of functionings, resources may well need to be distributed unevenly. Moreover, even if two persons possess the same levels of capabilities, their resultant achieved functionings may differ. This is because each person possesses the freedom to choose from a bundle of achievable functionings. This freedom, for Sen, is of intrinsic importance to human lives. Capabilities, therefore, represent substantive freedom: the extent to which a person can choose a way of life from a bunch of realistically achievable alternatives. Despite the obvious technical difficulty in measuring capabilities-as opposed to achieved functionings - Sen insists that appraisals of human lives should be done on the level of capabilities.

Based on this understanding of poverty and deprivation, Sen (2000) elaborates on how relational features 
play significant parts in capability deprivation. He argues that being excluded from social relations can 'be constitutively a part of capability deprivation as well as instrumentally a cause of diverse capability failures' (p. 5, emphasis original). Social relations are constitutively important if being excluded from them is seen as a loss on its own, whereas they are instrumentally important if exclusion from them results in deprivation in other aspects of life, if not in itself damaging. For example, Sen considers that 'taking part in the life of the community' can be of constitutive importance to one's life (p. 4). On the other hand, 'being excluded from the opportunity to be employed or to receive credit may lead to economic impoverishment that may, in turn, lead to other deprivations (such as undernourishment or homelessness)' (p. 5). He further illustrates how persistent unemployment can lead to various losses in life, including the unlearning of skills, limited freedom of decision, ill-health, psychological misery, damage to human relations, as well as gender and racial inequality.

While Sen makes it clear that relational features are important in understanding and analysing various types of capability deprivation, he gives no clear indication as to what 'social relations' exactly mean. Nor does his analysis include what 'social inclusion' might look like. This article, therefore, extends his argument in these directions by linking it with sociological theories. If Sen's formulation of social exclusion is simply reversed, social inclusion may be understood as enabling access to social relations which could lead to the resolution or alleviation of capability deprivation. However, the root cause of social exclusion often lies in the social structure, and it is not easy to overturn structural exclusion. Therefore, the effort towards social inclusion is almost a never-ending process. It starts by identifying the 'socially excluded', after which a structure to include them is gradually constructed. This article attempts to consider, in the case of sport-based social inclusion programmes, how far such humble efforts are able to reach. Hence, the aforementioned two objectives parallel with the following two questions: (1) how can 'participating in a sport-based programme' be understood as inclusion in social relations of constitutive or instrumental importance to a person's capabilities; and (2) to what extent can sport contribute to building a more inclusive social structure?

\subsection{Nature of Social Exclusion and Inclusion in Three Case Studies}

Before moving to the conceptual discussion, this subsection explains the nature of social exclusion that each of the three case studies has tackled, and what their respective effort towards social inclusion looked like. Despite the variety of issues and geographical contexts, the beneficiaries of these projects can be considered as being severely deprived of their capabilities due to dysfunctional social relations. In addition, all three case study projects used football as the central element of their programmes to build supportive structures for the beneficiaries.

In the Scottish case, it was not only embedded in the context of then British urban policy conceptualising the multiple deprivations concentrated in post-industrial urban neighbourhoods as social exclusion (Social Exclusion Unit, 2001), but also the deprivation experienced by young people in that particular locality was deeply affected by relational features. In addition to the fact that it was generally deemed that they were disadvantaged in accessing decent educational and employment opportunities as well as other public services, they were geographically divided along the boundaries of housing estates due to the so-called 'territorial youth gangs' (Kintrea \& Suzuki, 2008). The main strategy for the case study project was to provide a range of opportunities for football and other diversionary leisure activities for those affected by territoriality, and then to signpost them to other opportunities leading to career development.

In the Basotho case, the main issue the case study project was tackling was the prevalence of HIV/AIDS and the resultant problems concerning AIDS orphans. Orphans tend to face a high risk of being excluded from families and becoming street children. In addition, the stigma attached to HIV/AIDS prevented young Basotho from taking a test as well as HIV/AIDS education. The project held a series of football tournaments coupled with HIV testing and football-based educational sessions so young people could be tested without being stigmatised. The project also accommodated a number of orphans and HIV positives as staff members. It has recently transformed its model to become an elite football club, competing in the Basotho premier league while providing training in business skills to young Basotho from disadvantaged backgrounds.

In the Japanese case, the project was started to enter a team for the Homeless World Cup in 2009, so as to provide an opportunity for the homeless to express themselves on an international stage as well as to gain self-confidence. Homelessness is one of the most severe manifestations of social exclusion, as those who are suffering from homelessness are frequently excluded from employment opportunities as well as kinship and friendship networks. The project initially placed an emphasis on connecting the players to employment opportunities, achieving some success, although it has now modified its approach to provide more long-term supportive relationships, which are expected to substitute the previously failed relationships with families and friends.

The following two subsections discuss how these separate processes towards a socially inclusive society can be theoretically formulated in relation to some sociological theories.

\subsection{Agency, Structure and Capabilities}

This subsection disentangles the personal and structural features of social exclusion and inclusion in relation to 
the concept of capabilities, introducing the traditional sociological debate of agency versus structure. The debate could be summarised as the 'contrast between an overarching "social structure" that determines our behaviour versus the ability of individuals to exercise their freedom in controlling their own actions' (Johnson, 2008, p. 12). In line with Giddens' (1984) structuration theory, this article considers that it works in both ways.

A person's capabilities are, indeed, determined by both agency and structure. A person's personal abilities are converted into functionings when presented with adequate opportunities. A highly skilled football player is not capable of achieving a functioning of 'playing football well', unless there are other people who agree to play football with him, open space of adequate size available, and a spherical object that could be used as a football. Likewise, for a person to be 'being employed', the person not only needs to be adequately skilled but also have access to the labour market where that type of skill is in short supply.

A case can be made, however, that capability deprivation is more concerned with structure than agency, since there are plenty of instances where people with sufficient skills are denied opportunities due to personal attributes such as gender, race or social class. Moreover, people with disadvantaged backgrounds are often denied the opportunities to acquire basic skills in the first place. Thus, agency could have more freedom in choosing a way of life if the social structure is transformed to be more 'socially inclusive'. The question is how this goal could be achieved in general, and by running sport-based inclusion programmes in particular.

Structuration theory holds that social structure is maintained by agency's voluntary actions in accordance with the conventional values. But agency also has the power to transform social structure by accumulating innovative social actions. When these innovative social actions accumulate to a sufficient degree, they become an established institutional structure.

Provision of sport-based inclusion programmes can be understood as social actions by programme providers aimed at social transformation. On the one hand, they are designed to empower programme participants by providing a supportive structure within which they not only can improve their abilities but also find opportunities to make use of them. On the other hand, in their effort to gain the necessary resources to run their programmes, programme providers often challenge the conventional perception towards the issues they are trying to tackle. How they do this is elaborated in the analysis section.

\subsection{Relevance of Sport-Based Social Relations and Process of Transformation towards Inclusive Society}

Drawing from the existing literature, at least four types of social relations may be on offer when a sport-based programme is provided:
- First, it provides opportunities for face-to-face human interaction. This could be vital for those who are severely lacking such opportunities, both constitutively and instrumentally;

- Second, it could be an opportunity to be associated with a social group. Often, those who are suffering from severe exclusion, e.g. homelessness, do not have the primary group that they feel attached to. A sport-based community could function as a primary group for such people;

- Third, participation in a sport-based programme means that the person is part of a formal organisational structure. This not only means that he or she can enjoy a range of benefits resulting from membership, but also that he or she may be able to exert power to change the way the programme is run so that the structure it provides for the participants is more 'socially inclusive' (Coalter, 2007; Crabbe, 2005);

- Fourth, participants are presented with an opportunity to be part of a social network. The benefits of being linked to a social network, or social capital, depend on the nature of the network that the sport-based programme constructs. Potentially, it could provide both bonding and bridging capital for the participants. Good programmes often have strong bonding capital within the organisation while also being linked to broader organisational networks ensuring access to equally strong bridging capital (Coalter, 2013).

The purpose of this article is not to verify these separate potential mechanisms of social inclusion facilitated by a sport-based programme; the existing literature has already achieved this to varying degrees. Rather, it is concerned with the assessment of the potential: to what extent these mechanisms could accumulate to transform the exclusive nature of social structure?

To address this question, Johnson's (2008) three-way classification of sociological analysis provides a useful foundation. Johnson argues for the need for there to be an approach which integrates micro-, meso-, and macrolevel analyses to better understand the social world. The micro-level analysis focuses on 'face-to-face interaction and personal relationships', while the macro-level analysis focuses on 'larger-scale social systems, including the overall society' (p. 8). Between these extremes are 'various intermediate or "meso" level structures or social formations' (p. 9) through which micro and macro levels are linked to each other. Such meso-level social formations include organisations, along with communities, markets and socioeconomic classes.

This article applies this classification to the analysis of sport-based social inclusion programmes. The microlevel analysis would focus on the way the face-to-face interaction leads to social inclusion of programmes' participants, through the above-mentioned four mechanisms. The majority of the existing literature has focused on this 
level, and the knowledge has been accumulated in terms of the nature of effective programmes.

The meso-level analysis would focus on processes as to how an organisation transforms itself over time to become able to provide more 'socially inclusive' organisational structures. An organisation learns to improve itself so that it can accommodate many more of the 'socially excluded' (size), in the way that their extent of 'inclusion' be more profound (quality). The impact of a programme on social structure depends on its size multiplied by its quality. While the importance of these processes has been highlighted in the literature (Coalter, 2010; Crabbe, 2006), there still is much room for exploration.

The macro-level analysis would look at the process of development as a sector, or the organisational population. The number of organisations striving to use sport for the purpose of social change has been on the increase in the last few decades (Levermore \& Beacom, 2009). When the number of a certain type of organisation reaches a certain level, it is deemed 'institutionalised' (Scott, 2014). As it moves towards institutionalisation, it inevitably interacts with, and transforms, the convention of the broader institution so that the growth of the sector is possible. Few studies have attempted to assess the potential at this level, though it ultimately determines the impact on the macro structure.

\section{Analysis}

This section analyses how three levels of analysis combine to enable the evaluation of sport's impact on structural transformation towards a more inclusive society. First, at the micro level, the types of functionings that could, or should, be included in the evaluation of a sportbased social inclusion programme are discussed. The discussion consists of both normative argument and empirical evidence from the three case studies. Then, at meso and macro levels, it is shown how the accumulation of improved capabilities at micro levels can lead to structural transformation through organisational learning and legitimation.

\subsection{Micro-Level Analysis}

\subsubsection{Constitutive Relevance of Participation}

First, simply 'being connected' to social relations in itself is of constitutive relevance to one's life. From the viewpoint of the capability approach, the value of a sportbased programme in terms of this functioning is determined by its marginal value to one's capabilities. Among those who are labelled as being 'socially excluded', the relative severity of their deprivation in this sense may well vary significantly. In the case of the Scottish study, staff members often highlighted the fact that some of their participants were suffering from dysfunctional family environments, and the programme was to offer an alternative place where they could 'feel safe'. Similarly, most staff members who were recruited locally in the Basotho case expressed their gratitude to the programme saying 'I am who I am, because of it', although they were reluctant to elaborate on how 'bad' their previous experiences had been. In the Japanese case, the members who experienced a spell of homelessness had often totally lost contact with their families and friends. Its football practice sessions, therefore, provided them with precious opportunities of simply 'being connected'. Hence, a sport-based programme could function as a primary group for those who would otherwise be extremely isolated.

\subsection{2. 'Spending Time for Leisure'}

Second, participating in a sport-based programme instrumentally opens up opportunities to improve capabilities in terms of other functionings. Three categories can be commonly identified. The first is concerned with the functioning of 'playing sport'. It would be too optimistic, however, to presume that 'playing a particular type of sport' is of constitutive importance to every individual. Rather, it would be more agreeable to think that 'playing a particular type of sport', or even 'playing sport in general', is only relevant through its contribution to the capabilities in terms of the functioning of 'spending time for leisure' (Suzuki, 2005). Given the diversity of interests in leisure, it is important to make a diverse range of leisure activities available so that levels of substantive freedom are as equal as possible. As with the discussion above, regarding the constitutive relevance of 'being connected', attention must be paid to relativity of deprivation in terms of this functioning.

The Scottish case was aware of this importance and had incrementally developed a broad range of 'fun' activities through consultation with participants, and the relative importance of football coaching, which had been their core service, decreased over time. Football attracted 'hundreds' of boys, but in Glasgow, opportunities for football were relatively abundant compared to other leisure activities, even in deprived neighbourhoods. It was perceived that girls were more deprived in terms of leisure opportunities. Thus, activities more suited for girls were constantly provided through the 'Friday dropin' service. In contrast, the other two cases made deliberate decisions to stick to football, which was deemed central to their organisational identity. This may be justifiable as long as it has instrumental importance to the broadening of organisational structure so the capabilities of many more people could be more profoundly improved (as discussed below).

\subsubsection{Physical and Psychological Well-Beings}

The second category of important functionings is concerned with physical and psychological well-being. The evidence concerning physical and psychological benefits of sport-based programmes is relatively abundant in 
the literature. Although the three studies involved no systematic measurement, much qualitative evidence indicated their participants enjoyed psychological benefits resulting from a sense of belonging as well as improvements in their self-esteem and confidence. In the Japanese case study, some also exhibited significant improvement in terms of their physical health, as consultation with the staff members had led to proper medical treatment. As with the latter example, because they are all inter-related, it is hard to disentangle what the instrumental effects of 'playing sport', 'spending time for leisure' or 'being connected' are. One thing for certain, is the fact that they occur simultaneously in the midst of social interactions facilitated by the programme.

\subsubsection{Practical Benefits}

The third category can be labelled as practical benefits. This category is broadly concerned with 'employability'. All three cases aspired to help their participants to access employment opportunities. Indeed, it is known that many good practices structure themselves to progressively provide opportunities for the participants to become employed within the programmes (Burnett, 2010). The Scottish and Basotho cases clearly had such structures in place. The Scottish case assisted their relatively senior participants (aged 16+) to get experience of volunteering, to acquire coaching qualifications, and to be paid as sessional and then part-time staff. In the Basotho case, approximately half of the 20+ staff members were locally recruited, with some being gradually promoted from occasional volunteers to paid staff, and then on to managerial positions. The Japanese case did not have such elaborate internal structures but had been through several changes in its approach to assisting participants to gain employment opportunities elsewhere (as revisited below). Again, the element of sport may or may not be of direct relevance; some of the positions are related to football or sport, but many others are more generic.

\subsubsection{Sustainability as Necessary Condition}

Finally, the interplay between constitutive and instrumental relevance of sport-based social relations is worth noting. For the above-mentioned benefits to accrue, a necessary condition is that the participants stay connected to these opportunities over a prolonged period of time. 'Being connected' should be permanent. Oneoff provision of leisure activities is not so much of an addition to leisure capabilities. Achieving improvement in psychological and physical well-being normally takes time. And progressive promotion of employment takes a matter of years. While it is necessary for the organisation to persist, it is also necessary for participants to demonstrate commitment to the programme. The elements of sport perhaps play a significant role here. In other words, the activities on offer probably need to be of significant constitutive value to the person to be 'in- cluded'. The choice of a dominant sport such as football by the three cases may be justifiable in this regard.

\subsection{Meso-Level Analysis}

\subsubsection{Size v. Quality}

The micro-level processes of social inclusion within a sport-based programme occur at varying scales and with varying quality. One way of making the impact on structure greater is to improve on both fronts. However, this is more easily said than done. Organisations learn to do this in the process of sustaining and developing themselves.

In fact, general agreement in the literature is that size can often undermine quality (Crabbe et al., 2006; Nichols, 2007). A programme that attracts a large number of participants tends to be short-term and thus positive personal changes cannot be expected. On the other hand, a programme that provides continuous support for participants, and thus is more likely to make positive change, tends to be small in size. Crabbe et al. (2006) formulate this dichotomy as diversionary versus developmental approaches. As discussed above, the constitutive relevance of sport-based social relations should be permanent, and it takes multiple years for the instrumental relevance to materialise. This indicates the obvious superiority of the developmental approach over the simple diversionary approach. The question here, therefore, is how and to what extent an organisation employing a developmental approach could grow without losing quality.

The three cases illustrate such struggles. The Basotho case went for size first, employing an event-based approach borrowing a proven method of HIV/AIDS education and testing through football. It succeeded in graduating thousands of participants in the first few years, which led to instant recognition, and a number of best practice awards. However, it was soon learnt that it had stretched its resources too far to be able to continually monitor the graduates' progress. Thus, it refocused its strategy to restrict its geographical scope to the capital city Maseru and the surrounding areas. In contrast, the Japanese case struggled to gain sufficient numbers, with its members often leaving the programme after a couple of years. The programme now prioritises continuity of membership over size to support prolonged struggles of its beneficiaries in escaping homelessness. The Scottish case managed size and quality very well, balancing large-scale diversionary events as well as more focused, developmental approaches involving patient relationship building.

These varying experiences suggest that the relationship between size and quality is not a simple trade-off. A programme needs sustainability to improve its quality, and large size helps maintain the sustainability of resources, as funders tend to respond to numbers. Often, size goes with diversification, so as to accommodate the diversified needs of those who seemingly fall in the same category of 'exclusion' (see discussion above regarding 
relative leisure deprivation of girls in the Scottish case). Diversification is important as it means that more choices are available for the beneficiaries, and thus they are better off in terms of capabilities.

\subsubsection{Trajectories of Growth}

The balancing of size and quality is influenced by communication at two distinct interfaces. One is between programme participants and the organisers of the programme. The other is between the organisation and the environment it is dependent on for its existence. At the first interface, programme organisers meet the 'excluded'. The more they encounter their beneficiaries, the better they understand the issues they strive to tackle. At the second interface, programme organisers negotiate with potential providers of resources. In other words, they take actions to gain legitimacy of the programme (Scott, 2014). At both interfaces, programme organisers are engaged in a continual learning process.

As a result of such learning processes, programmes can go through very distinctive trajectories of transformation. The three cases each experienced several rounds of major transformation, adjusting to the needs of their respective beneficiaries, as well as what the environment demanded (Table 1). In fact, these demands often conflict with each other. Since an organisation is under the influence of institution, it could impose conventional values on its members. Meanwhile, an organisation could also represent an innovative set of values exhibited by its members (Scott, 2014). Legitimation may well be achieved relatively easily when it conforms to conventions, but as an agent for social change, challenging the exclusive conventions through negotiation is essential.

The experience of the Japanese case indicates how difficult it can be to balance the two. At first, the main purpose of the launch of the programme was to participate in the Homeless World Cup, which had already established itself at the global level. Most of the members who made to the tournament on two occasions (in 2009 and 2011) succeeded in getting employed shortly after the respective events. At that time, the programme organisers were motivated to press them in that direction, with its football practice sessions valuing competitiveness and self-discipline. However, the jobs they got were hardly permanent, and many experienced increased levels of isolation and/or difficulty in building relationships with new work colleagues. As a result, the majority soon went back to being unemployed, of which only a few remained connected to the football programme. This experience, coupled with the fall in the number of participants, led to the decision to relax the atmosphere of regular practice sessions, and the Diversity Cup was invented. This is a five-a-side football tournament held twice a year, linking a range of other 'social inclusion' organisations, so that different types of 'excluded' people can interact with one another within a non-competitive, relaxed environment. Consequently, the programme is now able to provide more customised and prolonged support for each participant, without hurrying him/her into employment. Yet, this poses a new challenge with regard to legitimation, because allowing the homeless 'just to play football' does not align well with the dominant perception in Japan of seeing the homeless as 'lazy free-riders'.

\subsection{Macro-Level Analysis}

The third level of analysis can be made on the macro level. While the meso-level analysis was directed at the process of organisational growth of each programme, this third level is concerned with the population of organisations. When a certain type of organisation grows in number, the effort for legitimation at organisational level accumulates to transform the conventional institution. The 'organisational field' is formed, and the type eventually becomes institutionalised (Johnson, 2008; Scott, 2014). This process is called legitimation at the level of organisational population.

Hannan and Freeman's (1989) density dependence model explains the relationship between the population size, or density, and the speed of growth. When a new type of organisation is conceived, its population growth is slow at first. As the number increases, the type of organisation gains legitimacy and more resources become available, so the population growth rate accelerates. Fi-

Table 1. Programme transformation of three case studies.

\begin{tabular}{llll}
\hline Phase & Scottish case & Basotho case & Japanese case \\
\hline I & $\begin{array}{l}\text { Geographical expansion of } \\
\text { football coaching programme }\end{array}$ & $\begin{array}{l}\text { Event-based HIV/AIDS education } \\
\text { and testing using established } \\
\text { method }\end{array}$ & $\begin{array}{l}\text { Participation in Homeless World } \\
\text { Cup for positive life experience }\end{array}$ \\
\hline II & $\begin{array}{l}\text { Diversification of programme } \\
\text { centred on Friday drop-in service }\end{array}$ & $\begin{array}{l}\text { Geographically-focused } \\
\text { implementation + development } \\
\text { of original curriculum }\end{array}$ & $\begin{array}{l}\text { Emphasis on employment and } \\
\text { 'independence' of members }\end{array}$ \\
\hline III & Increased focus on outward & $\begin{array}{l}\text { Competitive football club as } \\
\text { social enterprise focusing on } \\
\text { career development of youth }\end{array}$ & Focus on continuous relationship \\
& building + launch of Diversity Cup
\end{tabular}


nally, it slows down in the end, as the size of the organisation becomes saturated compared to the available resources and the competition between organisations intensifies. This results in either a plateau or decrease in its population.

This model indicates that there is a limit to the size of the population. This could be considered as the limit of structural change facilitated by sport-based social inclusion programmes. A study on this level is hard to conduct due to lack of reliable population data. Indeed, there are no statistics to definitively represent the population of organisations established for the purpose of sport for social inclusion. One approximate data set which one could use is the database of SDP organisations registered on the International Platform of Sport for Development. Far from being an exhaustive list of existing SDP organisations, it is arguably the most comprehensive. Using this database, Suzuki and Kurosu (2012) provide an estimate of the growth process of non-governmental organisations and argue that a pattern similar to the density dependence model was observed. Though it may be too premature to conclude it has reached a plateau already, it seemed certain that the legitimation process occurred in the mid-2000s. It would be interesting to see how much room for population growth is left for SDP nongovernmental organisations, of which, according to Sen's definition, the majority can be understood as sport for social inclusion programmes.

\section{Conclusions}

This article has argued that scholarly analyses of sport for social inclusion should be targeted at the levels of individual organisations as well as the population of organisations. This is because it would facilitate understanding of the extent to which sport can contribute to structural transformation towards a more socially inclusive society. Applying a capability approach, a comprehensive evaluation framework has been proposed to assess the impact that sport-based programmes might potentially make on social structure. While much literature has focused on the micro processes of inclusion through sport, it is argued that greater emphasis should be placed on meso- and macro-level analyses, as these are the levels where the conventional institution is challenged and transformed through the processes of legitimation at organisational and population levels. This claim was substantiated by empirical evidence from case studies from three distinctively different cultural contexts.

The concept of capabilities has both analytical and normative implications. Understanding social inclusion as the process of resolving or alleviating capability deprivation derived from failed social relations provides a solid analytical foundation to approach both personal and structural changes towards social inclusion that sport could facilitate. A person's capabilities are dependent both on their personal abilities and on the openness of the social structure, but the social structure also deter- mines the extent to which a person is able to improve their abilities. Sport-based social relations could function as supportive meso-structures to a varying degree. The quality, as well as scale, of social relations, improves through organisational learning, which happens on two fronts: by meeting the beneficiaries on the ground and through negotiating with the environment to gain organisational legitimacy.

The aggregation of such struggles results in legitimation at the level of organisational population. The growth of population means institutionalisation of this particular type of practice, and thus a significant change in social structure. The number of sport-based social inclusion programmes has been on the increase during the last two decades, and legitimation seems to have occurred. However, there is a risk associated with saturation of the organisational field, which might sooner or later affect the quality as well as quantity of sport-based social inclusion programmes. More scholarly effort, therefore, needs to be devoted to institutional analyses of organisations running sport-based social inclusion programmes.

The capability approach places a normative emphasis on substantive freedom. The value of sport-based social relations is relative to other equivalent social relations providing similar functions for the 'socially excluded'. Given the fact that 'playing a particular type of sport' is not universally constitutive of everyone's wellbeing, social exclusion persists if sport is the only route for social inclusion. A particular type of sport may be useful in gaining legitimacy in certain contexts. It should not be forgotten, however, that interest-based social relations can cause social division as well. Sport can also act as a carrier of exclusive social institution. One must be conscious of such ambivalent roles of sport in social inclusion and exclusion to appreciate its real value to society.

\section{Acknowledgments}

I would like to thank all informants of the three studies that this article draws on. I owe Sayato Nakata so much for the richness of data we were able to gather for the Japanese study, as well as for our earlier discussion on how to theorise organisational processes in relation to social inclusion. Finally, I am grateful for my cheerful and intelligent colleagues of the Sport for Social Inclusion Working Committee, for such special moments we have shared all along.

\section{Conflict of Interests}

The author declares no conflict of interests.

\section{References}

Burnett, C. (2010). Sport-for-development approaches in the South African Context: A case study analysis. South African Journal for Research in Sport, Physical Education and Recreation, 32(1), 29-42. 
Coalter, F. (2002). Sport and community development: A manual (Sportscotland Research Report No. 86). Edinburgh: Sportscotland.

Coalter, F. (2007). A wider social role for sport: Who's keeping the score? London: Routledge.

Coalter, F. (2010). The politics of sport-for-development: limited focus programmes and broad gauge problems? International Review for the Sociology of Sport, 45(3), 295-314.

Coalter, F. (2013). Sport for development: What game are we playing? London: Routledge.

Coalter, F. (2015). Sport-for-change: Some thoughts from a sceptic. Social Inclusion, 3(3), 19-23.

Collins, M. F. (2003). Sport and social exclusion. London: Routledge.

Collins, M., \& Haudenhuyse, R. (2015). Social exclusion and austerity policies in England: The role of sports in a new area of social polarisation and inequality. Social Inclusion, 3(3), 5-18.

Crabbe, T. (2005). 'Getting to know you': Engagement and relationship building. First interim national positive futures case study research report. London: Home Office.

Crabbe, T. (2006). 'Going the distance': Impact, journeys and distance travelled. Third interim national positive futures case study report. London: Home Office.

Crabbe, T., Bailey, G., Blackshow, T., Brown, A., Choak, C., Gidley, B., . . \& \& Woodhouse, D. (2006). Knowing the score: Positive futures case study research: Final report. London: Home Office.

Giddens, A. (1984). The constitution of society. Berkley and Los Angeles: University of California Press.

Hannan, M. T., \& Freeman, J. (1989). Organizational ecology. Cambridge, MA: Harvard University Press.

Johnson, D. P. (2008). Contemporary sociological theory: An integrated multi-level approach. New York: Springer.

Kelly, L. (2010). 'Social inclusion' through sports-based interventions? Critical Social Policy, 31(1), 126-150.

Kintrea, K., \& Suzuki, N. (2008). Too much cohesion? Young people's territoriality in Glasgow and Edinburgh. In J. Flint \& D. Robinson (Eds.), 'Community' cohesion in crisis: New dimensions of diversity and difference (pp. 199-218). Bristol: Policy Press.

Levermore, R., \& Beacom, A. (2009). Sport and development: Mapping the field. In R. Levermore \& A. Beacom (Eds.), Sport and international development (pp. 1-25). Hampshire: Palgrave Macmillan.

Levitas, R. (1998). The inclusive society? Social exclusion and new labour. Basingstoke: Macmillan.

Long, J., Welch, M., Bramham, P., Butterfield, J., Hylton, K., \& Lloyd, E. (2002). Count me in: The dimensions of social inclusion through culture and sport. Leeds: Leeds Metropolitan University.

Nichols, G. (2007). Sport and crime reduction: The role of sports in tackling youth crime. London: Routledge.

Scott, W. R. (2014). Institutions and organizations: Ideas, interests, and identities. Thousand Oaks, CA: Sage.

Sen, A. (1992). Inequality reexamined. Oxford: Oxford University Press.

Sen, A. (1999). Development as freedom. Oxford: Oxford University Press.

Sen, A. (2000). Social exclusion: Concept, application, and scrutiny (Social Development Paper No. 1). Manila: Asian Development Bank.

Silver, H. (1994). Social exclusion and social solidarity: Three paradigms. International Labour Review, 133, 531-578.

Social Exclusion Unit. (2001). A new commitment to neighbourhood renewal: National strategy action plan. London: HMSO.

Spaaij, R., Magee, J., \& Jeanes, R. (2014). Sport and social exclusion in global society. London: Routledge.

Suzuki, N. (2005). Implications of Sen's capability approach for research into sport, social exclusion and young people. In K. Hylton, J. Long, \& A. Flintoff (Eds.), Evaluating sport and active leisure for young people (pp. 3-21). Eastbourne: Leisure Studies Association.

Suzuki, N. (2007). Sport and neighbourhood regeneration: Exploring the mechanisms of social inclusion through sport (PhD thesis). Faculty of Law, Business and Social Sciences, University of Glasgow, Glasgow, Scotland.

Suzuki, N. (2014, December). Kick4Life as a case of the 'new breed' of sport-in-development organisation. Paper presented at the 2nd International Symposium on International Development through Sport, Tokyo, Japan.

Suzuki, N., \& Kurosu, A. (2012, July). Towards an ecological understanding of 'sport and development' movement using organisational database. Paper presented at ISSA World Congress for the Sociology of Sport 2012, Glasgow, Scotland.

Svensson, P. G., \& Levine, J. (2017) Rethinking sport for development and peace: The capability approach. Sport in Society. doi:10.1080/17430437.2016.1269083

World Bank. (2013). Inclusion matters: The foundation for shared prosperity. Washington, DC: The World Bank.

\section{About the Author}

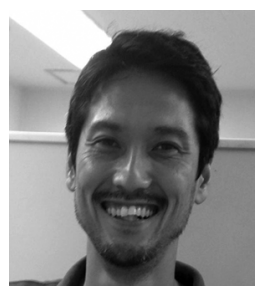

Naofumi Suzuki (PhD) is Associate Professor in the Graduate School of Social Sciences at Hitotsubashi University. His research interests include sport for development, urban and rural community regeneration, homelessness, social innovation, and social inclusion and exclusion. While mainly exploring the organisational processes of sport-based social inclusion programmes, he has also researched the social impact of sport-related urban development in relation to professional sport stadia in Europe and Japan, the 2010 FIFA World Cup in South Africa, the 1998 Winter Olympic Games in Nagano, and the 2020 Summer Olympic Games in Tokyo. 